

\title{
New Challenges to Old Standards in the Treatment of Rhinitis
}

\author{
Supported by an unrestricted educational \\ grant from Wallace Laboratories
}

The University of Texas College of Pharmacy is approved by the American Council on

Pharmaceutical Education as a provider of continuing pharmaceutical education. This program has been assigned ACPE \#067-999-01-156-H04 and will award 1.0 contact hour (0.1 CEU) of continuing pharmacy education credit to pharmacists who successfully complete the program. 


\section{EDITORIAL MISSION}

JMCP is dedicated to providing managed care pharmacists, associates, and students with the tools to excel in their daily practices by focusing on:

Policy: Providing a forum for in-depth discussion of issues of topical and long-term importance.

Practice: Presenting information of interest and educational value to the membership.

Research: Publishing research that increases the quality of research standards used in managed care pharmacy practice and helps apply that research 10 improve the practice of managed care pharmacy.

\section{EDITORIAL STAFF}

\section{Editor-In-Chief}

Craig S. Stern, R.Ph., M.B.A., Pharm.D., ProPharma Pharmaceutical Consultants, Inc., Northridge. CA

Publisher

Judith A. Cahill, Execulive Director, AMCP

Headquarters

\section{Editorial Advisory Board}

Robent J. Anderson, Pharm.D. Mercer University, Marietta, GA

Jean Brown, Ph.D., AdvancePCS, Fountain Hills, AZ Shane Desselle, Ph.D., Duquesne University, Pitsiburgh, $\mathrm{PA}$

Colonel George J. Dydek, Pharm.D., U.S. Army, Aberdeen Proving Ground, MD

Leslie Fish, Pharm.D. Fallon Healthare System, Worcester, $M A$

Richard E. Geller; R.Ph., CIGNA Healihcare, Glendale, $C A$

Diane B. Ginsburg, R.Ph., M.S., FA.S.H.P, University of Texas at Austin, College of Pharmacy, Austin, TX

Alan Heaton, Pham.D., Prime Therapeutics, St. Paul, MN

Tracy S. Hunter, Ph.D., Nova Southeastern Universily, Fort Lauderdale, FL

Eric G. Klein, Pham.D., Eli Lilly \& Co., Indianapolis, IN

Neil Mackinnon, Ph.D., Dalhousie University, College of Pharmacy, Halifax, Nova Scotia, Canada

Darlene Mednick, R.Ph., Merck-Medco Managed Care, LLC, Franklin Lakes, NJ

Michael J. Sax, Pharm.D., The Pharmacy Group, LLC, East Glasionbury, CT

\section{Founding Editor}

Louise J. Sargent, M.S., R.Ph.

Journal of Managed Care Pharmacy (ISSN 1083-4087) is peer-reviewed and published bimonthly by the Academy of Managed Care Pharmacy, 100 Nonth Pit Street, Suile 400, Alexandria, VA 22314; 703-683-8416; 800/TAP-AMCP; 703-683-8417 (fax). Periodicals

postage pending at Alexandria, VA, and additional mailing offices. Postmaster: Send address changes to address below:

\section{$A M C P$}

\section{AMCP HEADQUARTERS}

\section{North Pitt Street, Suite 400}

Alexandria, VA 2231.4

Tel: 703-683-8416; Fax: 703-683-8417

Copyright@ 2001. Academy of Managed Care Pharmacy, Inc. All rights reserved. No part of this publication may be reproduced or transmitted in any form or by any means, electronic or mechanical, without written permission from the Academy of Managed Care Pharmacy.

\section{About Supplements}

$\mathrm{T}$ he Journal of Managed Carc Pharmacy (JMCP) is pleased to present this supplement entitled "New Challenges to Old Standards in the Treatment of Rhinitis." JMCP educational supplements are specialized papers that deal with topics and issues related to managed care pharmacy. The purposes of supplements are to provide educational value to the reader, to exchange information, and to present focused content.
They are peer reviewed and subject to the same rigorous standards as the Journal.

This educational supplement discusses ways to improve the diagnosis and treatment of rhinitis in a way that also can contain costs.

This material was orginally presented as an AMCP 2000 satellite symposium, also sponsored by Wallace Laboratories.

Craig S. Stern, Editor-in-Chief

\section{F A C U L T}

William E. Berger, M.D., M.B.A., is Clinical Professor of Pediatrics in the Division of Allergy and Clinical Immunology at the University of California, Irvine, and adjunct Professor of Healthcare Management at the Graduate School of Management of the University of California, Irvine. In addition to his academic positions, Dr. Berger has a private practice in Mission Viejo, California, and is Medical Director at the Southern California Research Center, which he established for the purpose of focusing on respiratory-and allergy-related clinical research.

Omar Shoheiber, Pharm.D., is Vice President for Client Services at Tricore Technologies Inc., a technology-solutions company whose focus is on information management, marketing, sales training, and evidence-based marketing. Dr. Shoheiber is a visiting professor at Thomas Jefferson Medical College in Philadelphia, Pennsylvania, and the author of lectures, publications, and analyses on the topics of database analysis and cost of illness/cost of therapy models.

Grcg L. Ledgerwood, M.D., is Associate Clinical Professor of Family Practice at the University of Washington School of Medicine. His private practice, located in Omak, Washington, was established in 1974. For the past 10 years, Dr. Ledgerwood has specialized in allergy and chronic obstructive disease care. Dr. Ledgerwood has been lead allergist at the Wenatchee Valley Clinic in Wenatchee, Washington, and teaching coordinator for medical students and residents at the University of Washington School of Medicine. He is the author of numerous articles on family practice, allergy management, and asthma and has lectured at many national and regional meetings.

Eric Cannon, Pharm.D., is the Associate Director of Pharmacy Services for Intermountain Health Care (IHC), an integrated health care system with 23 hospitals, 68 physician clinics, 360 employed community-based physicians, and approximately 500,000 members. In his position at IHC, Dr. Cannon oversees projects aimed at controlling the cost and utilization of pharmaceuticals and directs pharmacy claims operations. Dr. Cannon is a member of IHC's Corporate Pharmacy and Therapeutics Committee, whose mission is to educate physicians and pharmacists about the effective use of pharmaceuticals and to promote formulary development and maintenance initiatives. Disease-management programs on which Dr. Cannon is currently working include protocols for depression, substance abuse, migraine, and pain management, as well as a rhinitis pilot program.

Diane B. Giaquinta, Pharm.D., is President of StrategiCare, a health care consulting company with a focus on managed care pharmacy, and the Director of Pharmacy Practice for Managed Care Interface. At StrategiCare, Dr. Giaquinta has provided consulting expertise in the areas of domestic and international health care strategy, new product launches, customer partnership development, value-added program development, training, and consumer marketing.

Dr. Giaquinta is Past President of the Academy of Managed Care Pharmacy and has held positions in many areas of the managed health care industry, including vice president of health systems management, Bristol Myers Squibb and vice president and general manager of Wellpoint Pharmacy Management. 


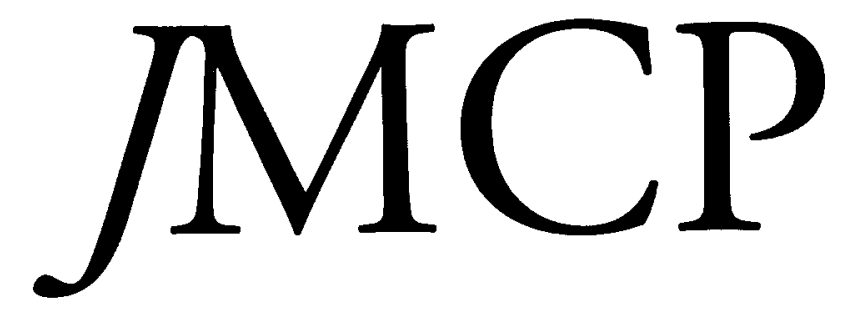

\section{$\begin{array}{llllllll}C & O & N & T & E & N & T & S\end{array}$}

\section{A Supplement to the Journal of Managed Care Pharmacy 8}

Introduction

An Etiology-Specific Diagnosis . . . . .5

Allergic Rhinitis . . . . . . . . . . . . 5

Nonallergic Rhinitis $\ldots \ldots \ldots \ldots \ldots$

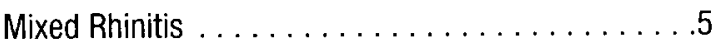

Treatment Choices .........................6

Mast Cell Stabilizers …............................................. 6

Anticholinergics ..................................................

Decongestants ..................................................

Intranasal Corticosteroids.................................... 7

Antihistamines ................................................. 7

Evaluating Utilization Patterns ...........7

Targeted Options

\section{TABLES}

Table 1-Risk Factors for Allergic Rhinitis

.5

Table 2-Members of the National Rhinitis Task Force . . . . . . . . . . . . . . 6

Table 3-Incidence of Allergic versus Nonallergic Rhinitis . . . . . . . . . .6

Table 4-A Comparison of Selected Product Indications . . . . . . . . . .

Table 5 -Target Drugs $\ldots \ldots \ldots \ldots \ldots \ldots$

Table 6-Initial Therapy by Physician Specialty
Combination Therapy 8

Medical Claims Analysis .......................................8

Cost of Care-Medical and Pharmacological .............9

- The Primary Care

Physician's Perspective ..................9

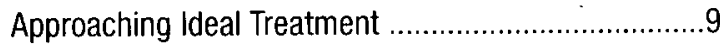

A Diagnostic Tool .............................................. 9

- The Health Care Plan Perspective ......10

Potential Solutions and a Pilot Program ...................10

Patient-directed Interventions ...............................12

Physician-directed Interventions ..........................12

Summary ..............................12

\section{FIGURES}

Figure 1-12-Month Prescription and Diagnosis Costs . . . . . . . . . . . . 9

Figure 2-Empiric Treatment with Drug-Effective Allergic Rhinitis Only ............10

Figure 3-Ideal Treatment Approach . . . . . . . . . . 10

Figure 4-Rhinitis Diagnostic Screening Tool . . . . .11

Figure 5-Disease-Management Process Map . . . . . 12 


\section{New Challenges to Old Standards in the Treatment of Rhinitis}

\section{Abstract}

"Although dozens of drugs have been introduced into the market recently, allergy sufferers are quick to point out that the overall management and effective treatment of allergies is sadly lacking."

- Frost \& Sullivan Survey (June 2000)

In addition to concerns over quality of treatment, the cost to treat rhinitis sufferers continues to rise. These costs are creating a substantial burden on the delivery of quality care in the cost-conscious managed-care environment.

An analysis in 2000 of pharmacy and medical claims data from three managed healthcare organizations revealed that most patients seek treatment from a primary care physician for allergy symptoms. Many claims for patients taking prescription medications for rhinitis do not carry a diagnosis code for allergic or nonallergic rhinitis and the patients appear to have been treated empirically. By performing a differential diagnosis aided by a rhinitis-screening tool, physicians have an opportunity to identify whether the etiology of the rhinitis symptoms is allergic or nonallergic. Proper diagnosis could lead to more appropriate treatment. Patients receiving appropriate care should have improved quality of life, fewer therapy switches, and fewer office visits for problems associated with inappropriate treatment.

Managed care organizations can better manage the cost and quality of treatment for their patient population through intervention that enables primary care physicians to diagnose rhinitis accurately at the first visit. The goal of this publication is to validate the need for differential diagnosis with minitis patients and to introduce an intervention program designed to lower costs by differentiating treatment for allergic and nonallergic rhinitis.

\section{Supplement Objectives}

After completing this continuing education program, participants should be able to:

- Differentiate the etiology and symptomatic presentation of nonallergic rhinitis from that of allergic rhinitis.

- Identify emerging treatment plans for patients presenting with nonallergic rhinitis.

- Illustrate the clinical and pharmacoeconomic importance of properly diagnosing and treating patients with nonallergic rhinitis.

- Focus on patients' positive response to appropriate therapy and the financial implications of inappropriate drug utilization.

- Describe the important role of managed care pharmacists in the development of strategies to successfully diagnose and treat nonallergic rhinitis.

Copyright 02001 Academy of Managed Care Pharmacy, Inc. All rights reserved.

This supplement is based on an accredited satellite symposium presented at the Academy of Managed Care Pharmacy Meeting on Wednesday, October 3. 2000, in San Diego, California.

\author{
by William E. Berger, Omar Shoheiber, Greg L. \\ Ledgerwood, Eric Cannon, and Diane B. Giaquinta
}

\section{Introduction}

Rhinitis is the fifth most common chronic illness reported in the United States today. Each year, it affects 62 million Americans who make 10,000,000 visits to doctors' offices seeking treatment.' These visits alone cost the health care industry $\$ 1.1$ billion; annual prescription drug expenditures for rhinitis treatments are $\$ 2.4$ billion.

There are other costs. Patients suffering from rhinitis lose 3.5 million school or work days a year and, as a direct result of their symptoms, they must restrict their activity 28 million days annually. Lost workplace productivity as a result costs American businesses $\$ 1,000$ per day, per worker.1.3

Patients may not clearly report rhinitis symptoms to their physicians. ${ }^{4}$ The symptoms, which include congestion, postnasal drip, fatigue, and persistent headache, often lead to difficulty in concentration and decision making. Symptoms in children include mouth-breathing, snoring, chronic cough, and throat-clearing. These symptoms can lead to a variety of common comorbidities, among them otitis media, asthma, sinusitis, and nasal polyps. ${ }^{5.6}$

There is increased concern about the costs of treating rhinitis in health plans. For most plans, allergy is one of the most expensive treatment categories, usually ranking among the top five. Pharmacy costs associated with antihistamines alone grew to more than $30 \%$ of total allergy treatment costs in $1999 .{ }^{7}$

In a telephone study conducted in 2000 by The GMR Group, 40 major metropolitan-area health plans with membership of more than 100,000 subscribers each were surveyed to ascertain how managed care is being affected by current treatment paradigms for allergic and nonallergic rhinitis. Pharmacy directors were asked to identify their concerns about the treatment of rhinitis. Their top concerns were:

- Are the therapies we are using effective?

- Are our patients being treated correctly?

- How can we control the growth in expenditures in this area?

- What effect are current disease-management measures having, if any?

- How much of our treatment cost is related to the influence of direct-to-consumer advertising?

The results suggest there may be room for improvement in 
how rhinitis is treated in the United States. According to the new Diagnosis and Management of Rhinitis: Complete Guidelines of the Joint Task Force on Practice Parameters in Allergy, Asthma and Immunology, "All too often, important causes of rhinitis go unrecognized by both physicians and patients. This leads to sub-optimal control of the disease."

\section{An Etiology-Specific Diagnosis}

Rhinitis is an inflammation of the membrane lining the nose that may be accompanied by rhinorrhea, sneezing, pruritis, and nasal congestion. These symptoms can result from an allergic or a nonallergic process. Accurately identifying the cause of symptoms can significantly improve diagnosis, treatment, and patient outcomes

A documented patient history is crucial to determining the etiology of rhinitis. A history should include:

- family history of allergy;

- patient's age at the onset of symptoms;

- patterns of symptom occurrence; and

- magnitude of the symptoms.

It is also important to inquire about the presence of allergens or irritants in the patient's home, work, school, and play environments and about recent changes in any of these. A simple diagnostic tool could help patients and physicians to better manage rhinitis by differentiating symptomatic presentation and manifestation. An example of such a tool is introduced below.

A physical examination is needed to identify any infections; to rule out structural abnormalities, such as a deviated septum, nasal polyp, or tumor; to identify any trauma-related symptoms (even microscopic trauma); and to identify related problems, such as asthma or otitis media. Clinical testing often includes skin-prick, nasal smear, and in some cases in-vitro testing.

\section{Allergic Rhinitis}

Current research trends point to a genetic model for allergic rhinitis, suggesting that it is likely to present in atopic persons or persons with a family history of a particular condition. In any one family, each member could exhibit symptoms in a different target organ. ${ }^{8}$ Thus a physician may see allergic rhinitis in one sibling and atopic dermatitis eczema in another. A third may have asthma and the parents might have any combination of the three. Table 1 , above, lists some common risk factors for allergic rhinitis.

Modern building codes and architectural styles encourage the creation of environments with limited air exchange and increased exposure to indoor allergens. Besides the dust mite, one of the most common indoor allergens, patients may be exposed to mold, dust, and animal allergens, such as feathers, hair, and dander from both cats and dogs. Patients with chronic allergic rhinitis experience symptoms caused by exposure to these allergens year-round.

Patients with seasonal allergic thinitis, on the other hand, may experience symptoms only during a few months of the year, after

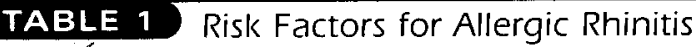

Family history of atopy

Positive allergy skin-prick test

Serum IgE levels > $100 \mathrm{IU} / \mathrm{ml}$ in children under six

Higher socioeconomic class

Non-white race

Residence in urban areas

Occurrence of symptoms before age 20

exposure to allergens such as grass, flower, weed, and tree pollens; hay; or mold. In general, these patients have decreasing tolerance for allergens as the season progresses, so that with time, increasingly smaller amounts of the allergen will induce symptoms. The allergy skin prick test will show-a positive reaction for these patients.

Physical symptoms of allergic rhinitis, which usually last more than 1.0 days, include purple shadows under the eyes; double creases under the lower lids (Dennie Morgan lines); repetitive sneezing; itchiness in the eyes, ears, nose, and palate; and clear rhinorrhea but no fever. 9

\section{Nonallergic Rhinitis}

Nonallergic rhinitis is nol a single condition; it is a group of syndromes sharing the following characteristics: ${ }^{10}$

- The condition is not caused by allergens.

- Its pathogenesis is usually unknown.

- Clinical testing reveals negative serum lgE levels.

The most common nonallergic rhinitis syndrome is vasomotor rhinitis, a condition affecting the blood vessels and nerve endings in the nose. Patients with perennial nonallergic rhinitis are extremely sensitive to changes in temperature and humidity. Symptoms, which may be chronic or acute, are often triggered by exposure to spicy foods, smoke, perfume, cosmetics, paint fumes, car exhaust, and cleaning supplies.

Nonallergic rhinitis with eosinophilia syndrome (NARES) is similar to vasomotor rhinitis except that eosinophils are present in the patient's nasal secretions, revealed through clinical testing."

Other nonallergic rhinitis syndromes include infectious and drug- or hormone-induced rhinitis. The cause of infectious rhinitis may be bacteria or viruses. Patients who take antihypertensives (such as reserpine) or hormone supplements (such estrogen or progesterone) may also experience rhinitis symptoms. Natural changes in hormone levels, such as those associated with pregnancy, also have been known to cause rhinitis. ${ }^{12}$

\section{Mixed Rhinitis}

In August 1.999, the National Rhinitis Classification Task Force was formed to determine the prevalence of allergic, nonallergic, and "mixed" rhinitis (allergic and nonallergic) in the allergist's practice. The task force conducted a retrospective review of 975 patient 


\begin{tabular}{|c|c|}
\hline TABLE 2 & $\begin{array}{l}\text { Members of the National Rhinitis } \\
\text { Task Force }\end{array}$ \\
\hline
\end{tabular}

Thomas Casale, M.D., Papillion, Nebraska

Mark Dykewicz, M.D., St. Louis, Missouri

Stanley Fineman, M.D., Marietta, Georgia

Clifton Furukawa, M.D., Seattle, Washington

David Golden, M.D., Owings Mills, Maryland

Gary Gross, M.D., Dallas, Texas

Michael Kaliner, M.D., Washington, D.C.

Dennis Ledford, M.D., Tampa, Florida

Phil Lieberman, M.D., Cordova, Tennessee

James Mallette, M.D., Florence, Alabama

Don Mitchel1, M.D., Jackson, Mississippi

Robert Reisman, M.D., Williamsville, New York

Richard Rosenthal, M.D., Great Falls, Virginia

Russell Settipane, M.D., Providence, Rhode Island

Sheldon Spector, M.D., Los Angeles, California

Michael Springer, M.D., Knoxville, Tennessee

William Storms, M.D., Colorado Springs, Colorado

Bruce Wolff, M.D., Nashville, Tennessee

\begin{tabular}{l|c|c}
\hline TABLE 3 & $\begin{array}{l}\text { Incidence of Allergic versus } \\
\text { Nonallergic Rhinitis }\end{array}$ \\
\hline Pure allergic & $\mathrm{n}=419$ & $43 \%$ \\
\hline Pure nonallergic & $\mathrm{n}=224$ & $23 \%$ \\
\hline Mixed & $\mathrm{n}=332$ & $34 \%$ \\
\hline Total & $\mathrm{n}=975$ & $100 \%$ \\
\hline
\end{tabular}

charts at the offices of 18 allergists (see Table 2, above) across the United States.

Reviewers first sought to categorize patients into two groups, "pure allergic" and "pure nonallergic." Pure allergic patients had to exhibit symptoms upon exposure to an allergen and react positively to a skin test and the patient's history had to show no infection, physical or structural defects, or environmental factors that might cause rhinitis. Of 975 patient charts reviewed, 43\% were identified as having pure allergic thinitis.

To belong to the "pure nonallergic" category, patients had to exhibit chronic, rather than seasonal, symptoms and skin test results had to be negative. Patient history often revealed nonallergic components, such as nasal polyps, tumors, deviated septa, infection, hormone use, medication use, or environmental exposures. Fewer than $25 \%$ of the patients whose charts were reviewed were identified as having pure nonallergic rhinitis (see Table 3, above)

Reviewers then looked at patients in the survey population who showed symptoms of both allergic and nonallergic rhinitis. They constituted $34 \%$ of the population. When these were combined with the pure nonallergic group, more than half $(57 \%)$ of rhinitis patients surveyed have a nonallergic component to their rhinitis. Applying these ratios to the population of 62 million Americans who suffer from rhinitis, 27 million people would have purely allergic rhinitis and 35 million people would have nonallergic or mixed.

The results of the task force survey thus suggest that the majority of patients require treatment that addresses either nonallergic or mixed symptoms. (It is important to remember that the survey was done using charts of patients who had consulted allergy specialists-patients who had already been diagnosed as having "allergy.")

Because the data in this document is conservative, the figures for the nonallergic/mixed combined category are likely to be even higher if charts for family-practice patients were also analyzed. A current survey evaluating the nonallergic components of rhinitis is incorporating primary care data to more accurately assess the impact of nonallergic and mixed rhinitis.

\section{Treatment Choices}

The true cause of rhinitis symptoms is often not identified because allergy skin tests are rarely part of routine office visits and patients are often unable to describe their triggers completely and correctly. Referrals to allergy specialists usually are made only after repeated failures of other treatments.

Physicians can (and do) recommend that patients avoid triggers, but avoidance only works if the triggers can be clearly identified and eliminated. A pharmacologic solution should be a safe, easy-to-use medication indicated for both allergic and nonallergic rhinitis symptoms, but current medications do not often meet all these objectives. Ineffective treatment options and unsuccessful outcomes can be frustrating to both patient and physician. Table 4 on page 7 lists some products commonly prescribed for rhinitis.

\section{Mast Cell Stabilizers}

Cromolyn sodium, an over-the-counter medication originally designed to treat asthma, has been prescribed for rhinitis for decades. Cromolyn sodium inhibits the degranulation of sensitive mast cells, thus inhibiting the release of mediators of allergic response and inflammation. Physicians use it often, especially for pregnant women and children. While it is very safe, has few side effects, and does address both early and late amylic phase reactions, it is not very effective, especially for patients who have acule symptoms. ${ }^{13}$

For optimal benefit, cromolyn sodium must be taken before exposure to an allergen and the nasal passages must be patent, which may require an additional prescription for a nasal decongestant. Acute symptoms treated with cromolyn sodium may require the addition of an antihistamine-decongestant combination. The product must be used throughout the allergy season. There is no evidence that cromolyn sodium is an effective treatment for vasomotor thinitis. ${ }^{13,14}$ 


\section{Anticholinergics}

Ipratropium bromide, another safe medication with few side effects, is useful in treating rhinorrhea but will not address allergic symptoms. Ipratropium bromide is a quaternary amine that minimally crosses the nasal and gastrointestinal membrane, reducing systemic anticholinergic effects. ${ }^{15,16}$ Although it can be combined with nasal steroids to treat rhinitis, ipratropium bromide is not very effective for vasomotor rhinitis.

\section{Decongestants}

Topical decongestants like pseudoephedrine are systemic medications that may alleviate nasal congestion. However, they may have adverse effects, such as loss of appetite, anxiety, nervousness, and insomnia. Patients who have an arrhythmia, angina, hypertension, or hyperthyroidism are not good candidates for these medications because they can aggravate these conditions. The Food and Drug Administration (FDA) recently issued a recall for all products containing phenylpropanolamine (PPA) due to safety concerns.

Topical decongestants like oxymetazoline can be effective in treating rhinitis-induced congestion but only for fewer than four days. Longer use may lead to rhinitis medicamentosa or "rebound" congestion. ${ }^{17}$

\section{Intranasal Corticosteroids}

Beclomethasone dipropionate, budesonide, and flucticasone are all nasal corticosteroids that have been approved for treatment of seasonal allergic thinitis and perennial nonallergic thinitis. Their localized anti-inflammatory activity and minimal systemic absorption make them very effective. Side effects include nasal irritation and nasal bleeding. Because they are steroids, there is some concern about growth suppression in children. Current FDA guidelines require that children younger than 12 who receive either nasal or inhaled steroids be measured regularly using a stadiometer. ${ }^{18}$

\section{Antihistamines}

Antihistamine options include either first- or second-generation oral antihistamines and a nasal antihistamine. Because first-generation oral antihistamines, such as diphenhydramine and hydroxyzine, are considered strong sedatives, they are usually not first-line choices for most patients. Loratadine and fexofenadine, both second-generation oral antihistamines, are effective in reducing sneezing, itching, and rhinorrhea, but they have minimal effects on nasal congestion and postnasal drip. Therefore, they may be prescribed in combination with other medications. ${ }^{+}$

Like second-generation oral antihistamines, the nasal antihistamine azelastine has an onset of action within three hours. It is the only second-generation antihistamine to be approved to treat seasonal allergic rhinitis in adults and children age 5 and over, as well as nonallergic vasomotor rhinitis in adults and children age 12 and over. It is effective in treating the symptoms of rhinitis, including

\begin{tabular}{|c|c|c|}
\hline & $\begin{array}{c}\text { Seasonal Allergic } \\
\text { Rhinitis }\end{array}$ & $\begin{array}{l}\text { Nonallergic } \\
\text { Rhinitis }\end{array}$ \\
\hline Claritin & $\checkmark$ & \\
\hline Allegra & $\checkmark$ & \\
\hline Zyrtec & $\checkmark$ & \\
\hline Astelin & $\checkmark$ & $\checkmark$ \\
\hline Beconase AQ & $\checkmark$ & $\checkmark$ \\
\hline Flonase & $\checkmark$ & $\checkmark$ \\
\hline Nasacort & $\checkmark$ & \\
\hline Nasonex & $\checkmark$ & \\
\hline Rhinocort & $\checkmark$ & $\checkmark$ \\
\hline Rhinocort AQ & $\checkmark$ & \\
\hline Vancenase AQ & $\checkmark$ & $\checkmark$ \\
\hline \multicolumn{3}{|c|}{$\begin{array}{l}\text { Note: Claritin, Nasonex, and Vancenase are trademarks of Schering-Plough. } \\
\text { Allegra and Nasacort are trademarks of Aventis. Rhinocort is an AstraZcneca } \\
\text { trademark. Beconase and Flonase are trademarks of GlaxoSmithKline and Zyrtec } \\
\text { is a Pfizer trademark. }\end{array}$} \\
\hline
\end{tabular}

\section{TABLE 5 Target Drugs}

Antihistamines - Oral Solids

- Claritin (loratadine)

- Zyrtec (cetirizine)

- Allegra (fexolenadine)

Antihistamines - Nasal Spray

- Astelin (azelastine)

Nasal Steroids

- Nasalide, Nasarel (flunisolide)

- Beconase, Beconase AQ, Beconase AQ DS, Vancenase,

- Vancenase AQ (beclomethasone)

- Nasacort, Nasacort AQ (triamcinolone)

- Rhinocort, Rhinocort AQ (budesonide)

- Flonase (fluticasone)

- Nasonex (mometasone)

nasal congestion and postnasal drip.+19 The most common side effects are bitter taste, headache, somnolence, and nasal burning.

\section{Evaluating Utilization Patterns}

Medication costs for treatment of rhinitis continue to rise, in some cases quite sharply. For example, in 1998, the cost of prescribed 
antihistamines was $\$ 8.33$ per health care plan member per year (PMPY). One year later, this figure rose to \$10.51, an increase of more than $25 \%$. Similarly, the PMPY cost for intranasal steroids jumped from \$3.59 PMPY in 1998 to $\$ 4.56 \mathrm{PMPY}$ in 1999.20.21

A patient analysis conducted in 2000 by Nelda Johnson and Omar Shoheiber of Tricore Technology, Inc., a technology-based information management company, was supported by Wallace Laboratories to explore several managed health care prescription-utilization and diagnostic indicators:

- What are the prescription patterns?

- What medical diagnoses are associated with prescriptions for second-generation antihistamines and nasal steroids?

- What are the resource-utilization patterns?

The retrospective database analysis used medical and pharmacy claims for three different health plans, each with a minimum of 1.00,000 members. One was located in the northeast, one in the north central, and one in the western part of the United States. Candidates for the study were plan members who had been continuously enrolled for at least 12 months with both medical and pharmacy coverage and who had received at least two of the target drugs. The target drugs are listed in Table 5 on page 7.

Of a starting sample population of 44,989 patients who had received one of the drugs, 19,325 patients were selected who had received more than one prescription for a target drug, indicating either a refill or another therapeutic option, and had been continuously enrolled in the health plan for 12 months or more. The mean age of patients was 35 years; $55 \%$ were female.

\section{Targeted Options}

The two categories of medication included were antihistamines (oral and nasal) (62\%) and nasal steroids (38\%). The average number of prescriptions for all target drugs was 4.5 prescriptions PMPY, at an average annual cost of $\$ 175$ per person.

Diagnoses analyzed, identified by 1 CD-9 codes, were allergic rhinitis, chronic rhinitis, acute sinusitis, chronic sinusitis, acute nasopharyngitis (common cold), and other diseases of the nasal cavity and sinuses.

The population was also analyzed according to the type of physician prescribing the target medication: primary care providers, 64\%; allergists, 14\%; ear, nose, and throat (ENT) specialists, $7 \%$; pulmonary specialists, $2 \%$; and other physicians, such as cardiologists, surgeons, and neurologists, $13 \%$.

\section{Combination Therapy}

Of the patients studied, $11 \%$ were started on combination therapy, usually antihistamine and a nasal steroid. Drugs were sometimes added to a treatment plan after an initial single-drug start. In all, $39 \%$ of patients in the study used two or more classes of medications during the one year follow-up period, perhaps as a result of treatment failure.

Allergists were most likely to recommend combination care from the start. Among primary care, allergy, ENT, and pulmonary care physicians, allergists prescribed initial combination therapy $20 \%$ of the time-about twice as often as primary care physicians. Primary care physicians favored initial antihistamine therapy, choosing one of the target antihistamines $56 \%$ of the time. Initial therapy with nasal steroids was the first choice of both ENT specialists and pulmonologists (see Table 6, below).

The cost and number of prescriptions per person were greater than the study averages for the group receiving initial combination therapy: \$188 PMPY, compared with the study average of $\$ 175$. Similarly, the average number of prescriptions for combination therapy was 4.9 prescriptions compared to a study average of 4.5 .

\section{Medical Claims Analysis}

Examining the medical rather than pharmacy claims for these 19,325 patients produced further insights. Of the qualified patients (those continuously enrolled for more than one year who had prescriptions for one of the target drugs) medical claims showed that only $40 \%$ had one of the target diagnoses.

Among patients with a target primary diagnosis, the study authors identified some startling patterns in correlated therapies observable within 30 days of the diagnosis date. Pure antihistamines were prescribed $41 \%$ of the time in response to a diagnosis of acute sinusitis-a condition for which antihistamines are not indicated. Allergic rhinitis patients received antihistamine therapy $50 \%$ of the time, and combination therapy $29 \%$ of the time. It is unknown what proportion of the patients actual-

TABLE 6 Initial Therapy by Physician Specialty

\begin{tabular}{c|c|c|c}
\hline Physician Specialty & \multicolumn{3}{|c}{ Initial Therapy } \\
\hline & Nasal Steroids & Antihistamines & Combination \\
\hline Primary Care & $33 \%$ & $56 \%$ & $11 \%$ \\
\hline Allergist & $36 \%$ & $44 \%$ & $30 \%$ \\
\hline Ear, nose, and throat (ENT) & $60 \%$ & $39 \%$ & $10 \%$ \\
\hline
\end{tabular}


ly had mixed or pure (with no allergic components or etiology) nonallergic rhinitis. More than $60 \%$ of patients with common colds (diagnosis: acute nasopharyngitis) were given one of the targeted antihistamines.

\section{Cost of Care-Medical and Pharmacological}

The medical claims also showed that, most of the time (59\%), patients visited their primary care physicians for treatment of their rhinitis symptoms. On average the number of office visits resulting in one of the target diagnoses as a primary diagnosis was 0.6 visits per patient per year, at an average annual medical charge of $\$ 19$ per patient per year (PPPY).

Taking both medical and pharmacy expenditures into account, the greatest total cost per patient per year was associated with combination therapy at $\$ 210$, followed by oral antihistamines at $\$ 202$, and nasal steroids at \$177 PPPY. Treatment with nasal antihistamines had the lowest cost, $\$ 131$ (see Figure 1, right).

The data demonstrate that allergic rhinitis is treated mainly in the primary care setting. Up to $39 \%$ of patients are treated with multiple products. About $60 \%$ did not have a diagnosis matching one of the primary diagnoses studied. The absence of such diagnosis coupled with the significant use of multiple products suggests that physicians may be treating empirically. Whether these products are targeting the underlying causes of rhinitis is questionable.

\section{The Primary Care Physician's Perspective}

According to the reference study conducted by Tricore, only $40 \%$ of patients receiving prescriptions for rhinitis had a related diagnosis. Physicians today, especially primary care physicians, are experiencing greater demands on their time and may need to see more patients in a day and take care of patient complaints quickly without benefit of a complete history and exam. To provide some relief for their patients, physicians may choose an antihistamine, knowing that about half the time it will work.

Patients come to physicians armed with information from direct-to-consumer marketing, the popular press, or the Internet. They are requesting particular thinitis medications by name to treat their rhinitis symptoms. This therapeutic category is one of those most aggressively targeted by direct-to-consumer advertising. Patients further believe they have researched the topic well enough to know exactly what they need. According to the 2000 Novartis pharmacy benefit report, prescriptions in the category grew by over 30\% in 1999 .

When physicians empirically choose an antihistamine treatment, the outcomes can be predicted based on the nature of the patient's rhinitis symptoms. For the $43 \%$ of patients whose symptoms are purely allergic, antihistamine therapy will probably improve symptoms. For the $57 \%$ of patients whose symptoms are either purely nonallergic or mixed, antihistamine therapy will be only partially effective or ineffective (see Figure 2, page 10).

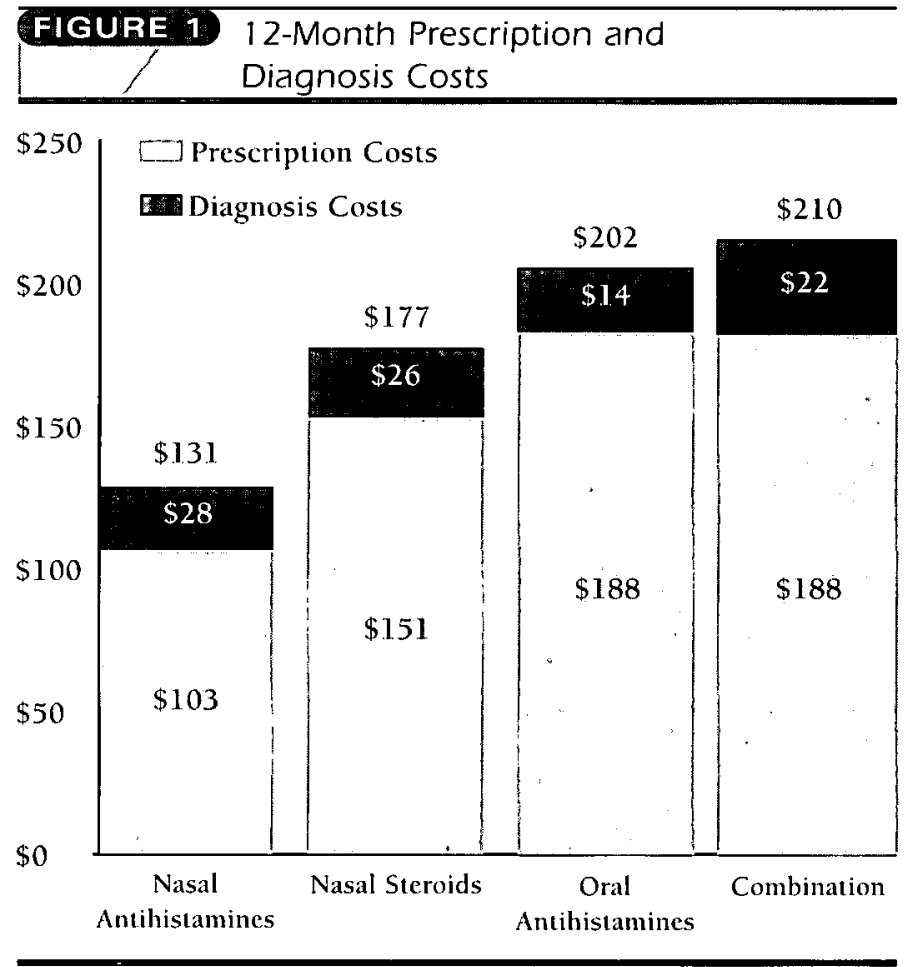

\section{Approaching Ideal Treatment}

A process in which less than half the patients treated get relief after their initial visits is not satisfactory. Physicians need a process that will bring greater patient satisfaction, yield better results in a shorter time, and be more cost effective.

As early as possible, patients who present with rhinitis symptoms should have their symptoms categorized as pure allergic, pure nonallergic, or mixed. Patients whose symptoms are purely allergic can be tested for potential allergens, be treated for their symptoms, and learn to remove or avoid those allergens. The remaining patients can then have their symptoms treated with an effective medication while causes are investigated (see Figure 3, page 1.0).

\section{A Diagnostic Tool}

For this ideal treatment approach to work, physicians must be able to establish a diagnosis quickly; they need a tool or a technique that integrates the patient into the process, one that would help patients understand the causes of their symptoms and guide their expectations about treatment.

Dr. Phillip Lieberman, clinical professor of medicine at the University of Tennessee School of Medicine, has developed a simple, self-administered screening tool designed to help patients and physicians identify rhinitis etiology (see Figure 4, page 11). The patient can complete the evaluation independent of the physician. With the data presented by the patient, the physician can easily conduct a focused patient assessment and choose the 


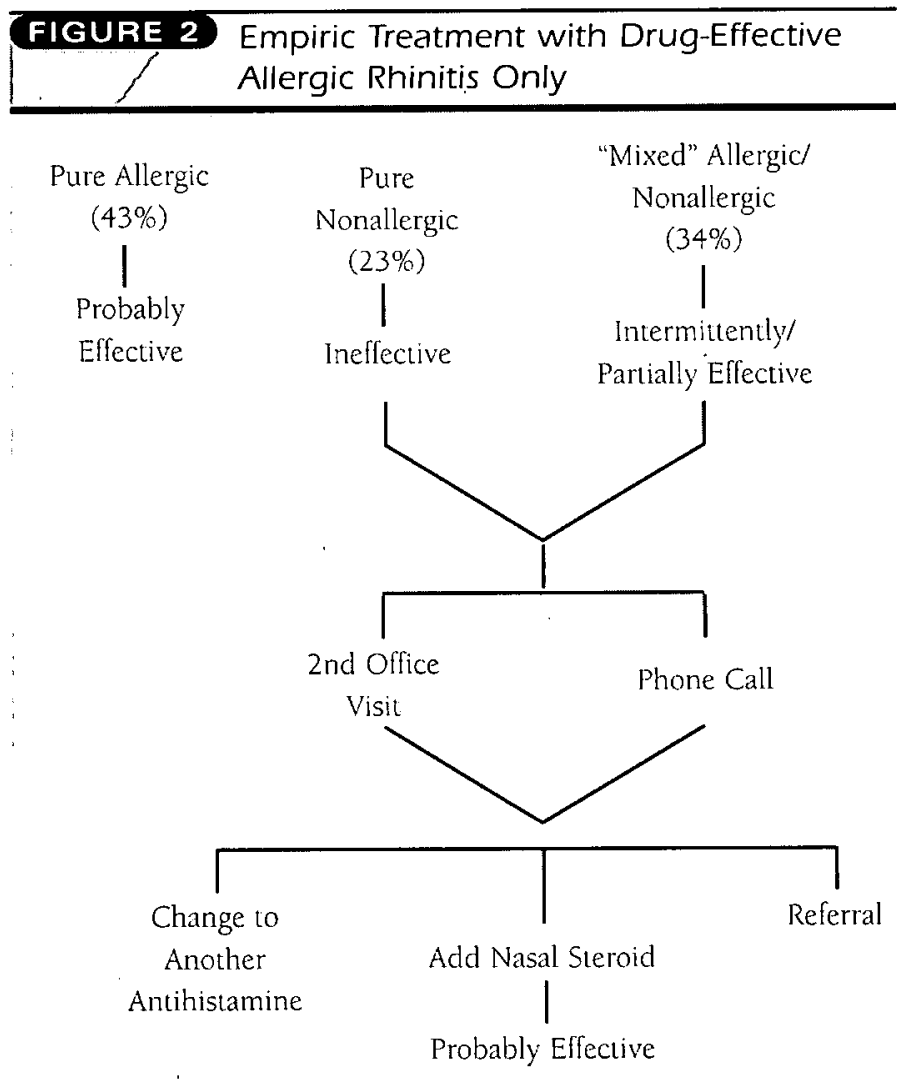

most appropriate treatment.

While this tool is not intended to be the sole determinant of a diagnosis, it may help patients understand their condition and know what outcomes to expect with treatment. Patients can identify their symptoms and pinpoint the months in which they occur. In addition to several helpful background questions about the onset and severity of symptoms, patients can identify factors that worsen their symptoms. The color-coded format makes the tool easy to read and interpret for both patient and physician.

\section{The Health Care Plan Perspective}

While The GMR Group was assessing the experience of managed care plans with rhinitis treatment, one group, Intermountain Health Care (IHC) in Utah, expressed great interest in managing the costs associated with rhinitis. IHC is comprised of 23 participating hospitals, 68 physician clinics and surgery centers, 360 employed community care physicians, and nearly half a million members.

Nonsedating second-generation antihistamines account for as much as $8 \%$ of IHC's prescription budget. In 2000, 45,000 members-nearly $10 \%$-were treated for rhinitis. While the national average for these medications was \$10.51 PMPY in 1999, IHC currently experiences a higher cost: $\$ 12.30$ PMPY. $^{20}$

The higher-than-average cost IHC experienced caused plan administrators to examine more closely how rhinitis is treated

\section{FIGURE 3}

Ideal Treatment Approach

Patient Presents With Rhinitis

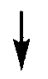

Determine Allergic, Nonallergic, or Mixed

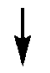

Remove Allergen/Trigger

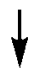

Treat Symptoms Appropriately

within the plan. Looking at both the National Rhinitis Classification Task Force survey results and the retrospective clatabase analysis, IHC administrators asked:

- Why is there such high use of antihistamines in diagnoses where it is inappropriate, such as acute sinusitis and common cold?

- How does increased time pressure affect our physicians' diagnostic practices?

- Can IHC reduce or eliminate inappropriate utilization of resources?

- How often does patient demand for a particular medication drive diagnosis?

Given the magnitude of cost experienced in this category, the pharmacoeconomic implications of the Tricore study and the work of the National Rhinitis Classification Task Force are significant. More appropriate use of products in this category may enable health plans to recognize substantial cost savings.

\section{Potential Solutions and a Pilot Program}

The pharmacy director at IHC (and in other plans that elect to undertake such an initiative) will play an integral role in developing and implementing strategic initiatives to improve the quality of patient care, examine current products on the formulary, control rising drug costs, and identify opportunities to improve patient care and better manage the cost of care for allergic and nonallergic rhinitis. The IHC pharmacy director is an advocate for finding a solution to the challenge of efficiently treating plan members suffering with rhinitis.

First, in a series of meetings with staff who would be working on the initiative, IHC identified four tactics to address the rising cost of treating rhinitis: sharing data with physicians; enhancing the diagnostic process through the use of a simple tool; educating patients, physicians, and employers; and implementing an intervention program.

These tactics then were incorporated into a pilot program designed to improve satisfaction for patients seeking treatment for rhinitis and for physicians who treat these patients, and to 
PATUENT RUUNUTUS SCREEN

This form will help determine the kind of rhinitis you have.

Please check the box next to your symptoms.

\begin{tabular}{|c|c|c|c|c|c|c|c|c|c|c|c|c|c|}
\hline \multirow[b]{2}{*}{$\begin{array}{l}\text { What symptoms } \\
\text { do you have? }\end{array}$} & \multicolumn{8}{|c|}{ When do you have symptoms? } & \multicolumn{4}{|c|}{$\begin{array}{r}\text { Age whon you } \\
\text { first started } \\
\text { having symptoms? }\end{array}$} & \multirow[b]{2}{*}{$\begin{array}{c}\text { All } \\
\text { year? }\end{array}$} \\
\hline & Jan & Feb & Mar & Apr & May & Jun & Jul & Aug & Sep & Oat & Nov & Dec & \\
\hline Sneezing & & & & & & & & & & & & & \\
\hline Stuffy nose/congestion & & & & & & & & & & & & & \\
\hline Runny nose & & & & & & & & & & & & & \\
\hline Postnasai drainage & & & & & & & & & & & & & \\
\hline Itchy eyes/itchy nose & & & & & & & & & & & & & \\
\hline
\end{tabular}

What medication(s) do you take for your symptoms?

Are your symptoms: $\square$ completely $\square$ controlled? $\square$ comewhat $\quad \square$ uncontrolled?

Patient: Please check all the things that you think make your symptoms worse:

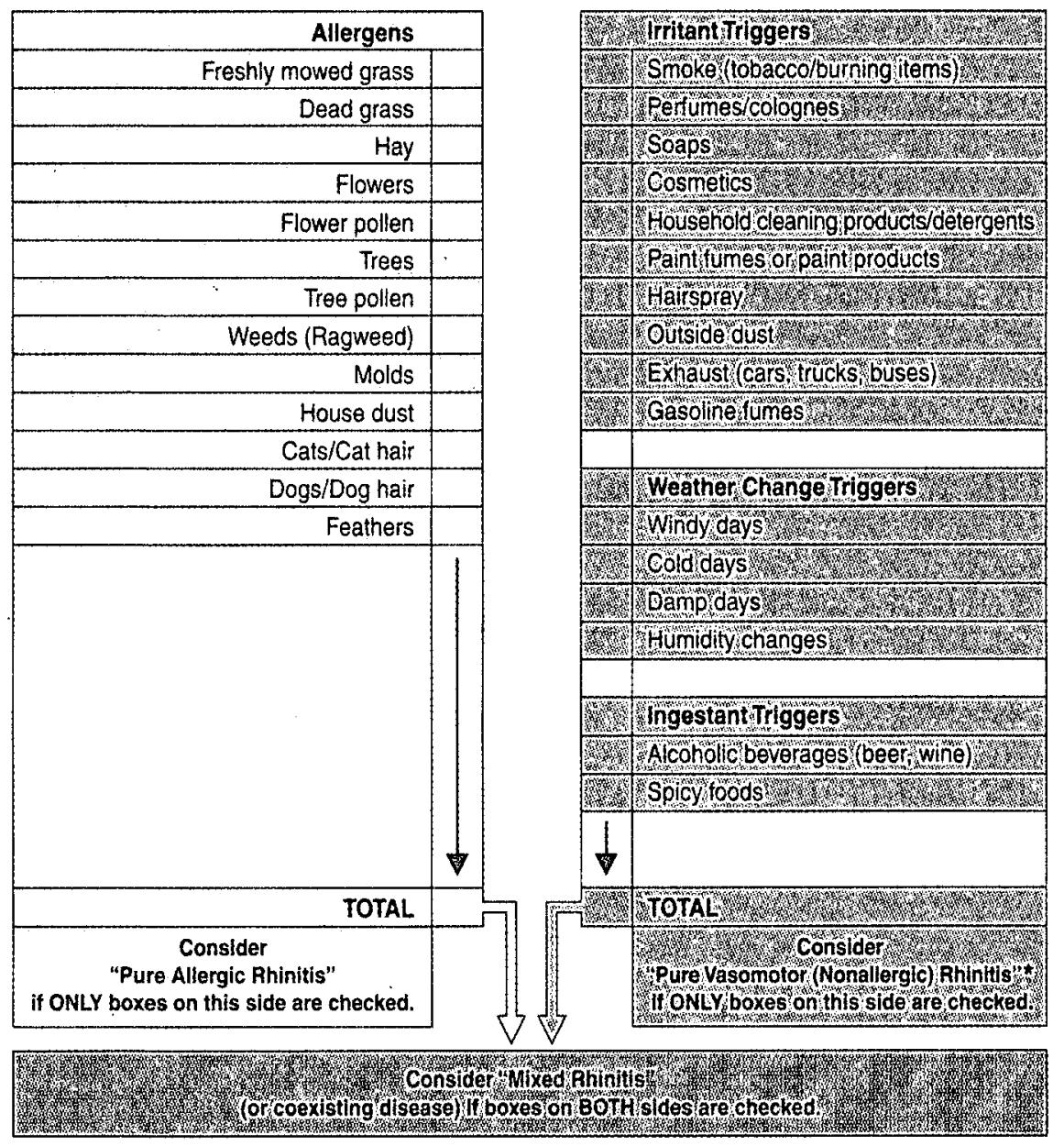

* Vasomotor minitis is the major type of nonatlergic minitis. Other types of nonallergic mintis include: infectious, hormonally-, exercise-, drug-, or reflex-induced etiologies, NARES and ciliary dyskinesia syndromes, and atrophic rhinitls. See guidolines by Dykowicz, et al for complete information (Ann Allergy Asthma Immunol. 1998;81:478-518). 
Define
Plan
Implement

Measure
Define objectives and values

Benchmark/segment total population

Identify target population

for Disease Management
Implement plan

- Communication

- Integrate tools

- Deploy

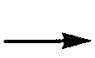

Reassess outcome measures vs. objectives and values

- Monitor

- Intervene evaluate the effectiveness of specific rhinitis disease-management techniques (see Figure 5, above).

IHC intends to first identify from 4 to 12 clinics that treat similar numbers of rhinitis patients and have similarly qualified physicians. These sites and physicians will be assigned to either a "usual care" group or the "disease-management" group. Once these are selected, patients will be selected, using pharmacy claims data, by whether they are receiving a target drug. Medical claims data will identify the ICD-9 diagnostic code recorded for each patient.

Surveyors will be looking for quantitative data, such as the percentage of patients using nasal steroids or antihistamines; the number of rhinitis-related office visits, the number of rhinitis-related medications per member per month; the percentage of patients who switch from medication to medication; and the impact on productivity, as measured by lost work days.

Other inquiries will look at patient and physician satisfaction with the disease-management program, patient knowledge about the disease, and the number of patients reporting disease-management problems (using a rhinitis-attack diary).

\section{Patient-directed Interventions}

The project offers a significant opportunity to educate patients and further integrate them into the treatment process. Patients will receive an initial mailing, containing material such as:

- a welcome letter explaining the participation selection criteria for the program;

- a brochure containing information about rhinitis and its treatment;

- a quality-of-life survey; and

- the Rhinitis Diagnostic Screening tool developed by Dr. Lieberman.

Patients will receive other mailings, including additional explanatory materials and periodic survey forms.

\section{Physician-directed Interventions}

Physicians who are members of the disease management group will receive an initial mailing, containing material such as:

- a welcome letter explaining the program;

- a list of rhinitis patients in their practice;

- copies of the patient-oriented material;

- a rhinitis diagnosis and management guideline; and

- the Rhinitis Diagnostic Screening tool developed by Dr. Lieberman.

Physicians will also receive follow-up mailings, keeping them informed about the study, including copies of information distributed to their patients by the managed care plan. Local educational programs will be designed to help physicians better help their patients.

IHC hopes that improving the differential diagnosis of allergic versus nonallergic rhinitis and better informing patients will result in more-efficient treatment and higher patient satisfaction.

\section{Summary}

Rhinitis is a very common disease, afflicting millions of people at great expense in medical care and prescription costs. Nearly half of all rhinitis patients exhibit symptoms that are either nonallergic or mixed, making it difficult for most physicians to diagnose the true nature of the disease. Symptoms of allergic and nonallergic rhinitis are often indistinguishable and the problem is compounded by current trends such as the demand for rapid diagnosis and direct-to-consumer advertising. Only a combination of close physical examination, focused patient history, and clinical testing can lead to a diagnosis that optimizes treatment.

Therapy is driven largely by primary care physicians, although there is a strong element of patient-driven therapy selection. Medications are often selected on an empirical basis, although these are often ineffective in addressing patient symp- 
toms, and are replaced or combined frequently in efforts to provide patient relief. If the initial diagnosis cannot be more accurate, the best first-line approach may be a medication that is safe and effective in treating both allergic and nonallergic symptoms.

To improve the accuracy of their diagnoses, physicians need to review patient history thoroughly. This can be simplified by the Rhinitis Diagnostic Screening Tool self-administered by patients for discussion with the primary care physician. It provides not only ample information for the physician to use in making a diagnosis, but also an opportunity for the patient to become part of the diagnostic team

Intermountain Health Care (IHC) has launched a pilot program using the screening tool for diagnosis of rhinitis in a segment of its membership. The program includes mailings to both the physician and the patient. The mailings will include information about rhinitis and the diagnostic tool, as well as support material. Claims data for patients in the pilot program will measure the effectiveness of the tool and the program.

Treatment of rhinitis is an area of medicine often taken for granted, as evidenced by the absence of differential diagnostic techniques as well as what appears to be excessive use of empirical therapy. These therapeutic categories offer significant opportunities for improving care

\section{References}

1. Blaiss M. How to determine the cost-effectiveness of available allergic rhinitis trealments. Drug Benefit Trends. 1998; 10(6): 32-36.

2. Storms $W$ et al. The economic impact of allergic rhinitis. I Allergy Clin Immunol. 1997; 99(6): \$820-24

3. Ross RN. Allergic rhinitis, an expensive disease for American business. Am J Man Care 1996; 2: 285-90

4. Dykewicz M, Fineman S. Diagnosis and management of rhinitis: complete guidelines of the joint lask force on practice parameters in allergy, asthma and immunology: Ann Allergy Asthma Immunol 1998; 81: 478-518.
5. Settipane RA. Complications of allergic rhinitis. Allergy Asthma Proc 1999; 20(4): 209-13.

6. Fireman P. Therapeutic approaches to allergic rhinitis: treating the child. J Allergy Clin Imnunol 2000: 105(6 Pt 2): S616-21.

7. Emron, an IMS Health company. Novartis pharmacy benefit report (2000 Edition). Totowa, N.J.: Emron.

8. Austen K. Diseases of immediate type hypersensitivity. Principles of internal medicine (14th ed, chap 310). New York, NY: McGraw-Hill, 1998.

9. Economides A, Kaliner M. Allergic thinitis. In Kaliner, M, ed, Current review of allergic diseases. Philadelphia: Current Medicine, Inc., 2000, 230-31

10. Druce $\mathrm{H}$. Allergic and nonallergic rhinitis. In Middleton $\mathrm{E}$, et al., eds. Allergy: principles and practice (4th ed). St. Louis: Mosby, 1.993, 1433-53.

11. Settipane, RS, Settipane GA. Nonallergic rhinitis. In Kaliner, MA, ed. Current review of allergic discase. Philadelphia: Current Medicine, 2000.

1.2. Mygind N. Anggard A, Druce HM. Definition, classification, and teminology lof rhinitis]. In Mygind N. Weeke B, eds. Allergic and vasomotor rhinitis. Copenhagen: Munksgaard, 1985, 15.

13. Altounyan REC. Review of clinical activity and mode of action of sodium cromoglycate. Clin Allergy 1980; 10: 481-89.

1.4. Nelson B1., Jacobs RL. Response of the nonallergic thinitis with eosinophila (NARES) syndrome to $4 \%$ cromolyn sodium nasal solution. J Allergy Clin Immunol 1982; 70: 125-28.

15. Wood CC et al. Product characteristics and pharmacokinetics of intranasal ipratropium bromide. J Allergy Clin Immunol 1995; 95: 1111-16.

16. Borum P et al. Ipratropium nasal spray: a new treatment for thinorthea in the common cold. Am Rev Respir Dis 1981; 123: 418-20.

17. Black MJ, Remsen KA. Rhinitis medicamentosa. Can Med Association J 1980; 122: 881 .

18. Class labeling for intranasal and orally inhaled corticosteroid-containing drug products. FDA Talk Paper 1998

19. Banov C, LaForce C, Lieberman P. Double-blind trial of Astelin(B) nasal spray in the treatment of vasomotor rhinitis. Annals of Allergy; Asthma, and Immunology 2000; 84(1)

20. Emron, an IMS Health company. Novartis pharmacy benefit report (1998 edition). Totowa, NJ: Emron.

21. Emron, an IMS Health company: Novartis pharmacy benefit report (1999 edition). Totowa, NJ: Emron. 


\section{New Challenges to Old Standards in the Treatment of Rhinitis}

Participant Name: Date:

Program Expiration Date: January 31, 2003

ACPE Universal Program Number: 067-999-01-156-H04. This continuing education program is made available through an educational grant from Wallace Laboratories.

To keep your supplement intact, please photocopy this form. Your assistance in the evaluation process is greatly appreciated. To provide anonymity, your name is not required. Please return this form to the address on page 16.

\section{SCALE FOR QUESTIONS $1-4$}

$1=\quad$ Not at all

$2=\quad$ Not very well

$3=$ $4=\quad$ Well

$5=\quad$ Very well

Using the scale above for Questions 1 through 4, please rate how well you will be able to accomplish the following objectives based upon successful completion of the program:

\section{Objectives}

1. Differentiate the etiology and symptomatic presentation of nonallergic rhinitis from that of allergic rhinitis

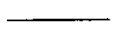

2. Identify emerging treatment plans for patients presenting with nonallergic rhinitis

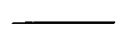

3. Illustrate the clinical and pharmacoeconomic importance of properly diagnosing and treating patients with nonallergic rhinitis; focus on the patient's positive response to appropriate therapy and the financial implications of inappropriate drug utilization

4. Describe the important role of managed care pharmacists in the development of strategies to successfully diagnose and treat nonallergic rhinitis in the managed care setting

Using the scale above right for Questions 5 through 7 , please indicate the number which best expresses your opinion:

5 . What is your overall rating for this program?

\section{SCALE FOR QUESTIONS $5-7$}

$\begin{array}{llll}1= & \text { Poor } & 4= & \text { Very good } \\ 2= & \text { Fair } & 5= & \text { Excellent } \\ 3= & \text { Good } & \end{array}$

6. How would you rate the pertinence of the program materials to your practice?

7. Please rate each of the following program aspects:
a. Content
b. Clarity
c. Knowledge gained

8. To what degree do you anticipate changes in patient care as a result of the material presented? (Circle one)

$\begin{array}{ccccc}1 & 2 & 3 & 4 & 5 \\ \text { No Change } & & & & \text { Significant Change }\end{array}$

9. Please indicate the length of time it took to complete this program: (Circle Selection)

$\begin{array}{lccc}\text { Hours: } & 1 & 2 & 3 \\ \text { Minutes: } & 0 & 15 & 30\end{array}$

10. Please rate the difficulty factor for completing this CE program: (Circle Selection)
Easy
Moderate
Difficult

11. Please rate your willingness to recommend this program to colleagues: (Circle Selection)
Very Willing
Willing
Not Willing

12. Please indicate which venue you prefer for obtaining continuing education: (Circle Selection)

Written monograph Slides

Videos Internet-based Live sessions 


\section{PARTICIPATION RECORD}

\section{New Challenges to Old Standards in the Treatment of Rhinitis}

Date:

Program Expiration Date: January 31, 2003

ACPE Universal Program Number: 067-999-01-156-H04

A continuing education program made available through an educational grant from Wallace Laboratories.

All information will be kept confidential; it is used only for the processing and mailing of your CE statement. You must complete and sign this form in order to receive CE credit for attending this program.

I verify that I have completed the program and post-test for "New Challenges to Old Standards in the Treatment of Rhinitis."

Please print your name as you would like it to appear on the CE statement:

Last Name:

First Name:

Address:

City:

State:

Zip:

Daytime Phone:

Social Security \#:

Fax Number:

E-mail:

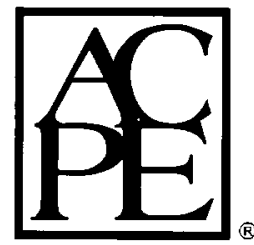

The University of Texas College of Pharmacy is approved by the American Council on Pharmaceutical Education as a provider of continuing pharmaceutical education.

This program is approved for 1.00 hour (0.1 CEUs) of continuing education for pharmacists who successfully complete the program. The ACPE Universal Program Number for this program is 067-999-01-156-H04. Successful completion of the program includes completing the program and post-test with a grade of at least $70 \%$ and submission of a completed Participation Record, Post-test and Evaluation Form. Upon successful completion of the program a CE statement will be mailed by The University of Texas directly to participants 4-6 weeks following receipt of the post-test and forms. Persons failing the post-test also will be notified.

Please mail the Evaluation Form on page 14, this Participation Form, and the Post-test on page 16 to the University of Texas at Austin address on page 16.

Program Expiration Date: January 31, 2003 
Please circle the correct answer.

1. Rhinitis can be properly diagnosed and treated without identifying whether the symptomatic origin is allergic or nonallergic.

True or False

2. Which of the following products have a Food and Drug Administration (FDA) indication for treating nonallergic rhinitis?
a. Claritin
b. Astelin
c. Allegra
d. Zyrtec

3. Which of the following is not a risk factor for allergic rhinitis:

a. Family history of atopy

b. Negative allergy skin prick test

c. Residence in urban areas

d. Serum IgE levels $>100 \mathrm{IU} / \mathrm{ml}$ in children under six

4. Physical symptoms of allergic rhinitis include several of the following; please select the answer that is not a physical symptom:
a. Itchiness of the eyes, ears, nose and palate
b. Repetitive sneezing
c. Fever
d. Clear rhinorrhea

5. Which of the following is not a symptom of a pure nonallergic patient:
a. Seasonal symptoms
b. Negative skin tests
c. Nonallergic components like nasal polyps, tumors, or infection
d. Exposure to environment factors

6. Nasal antihistamine azelastine is the only second-generation antihistamine approved to address the symptoms of seasonal allergic rhinitis in adults and children over the age of 5 as well as the symptoms of nonallergic vaso motor rhinitis in adults and children over the age of 12 .

True or False

\section{According to the data analysis} discussed in the article, which category of physician is the most common prescriber of target medications for allergy symptoms:
a. Allergist
b. Ear, nose, throat specialist
c. Primary-care physician
d. Pulmonary specialist

8. Which of the following is not an assessment question covered in the screening tool developed by $\mathrm{Dr}$. Phillip Lieberman?

a. Onsel of symptoms
b. Months of the year when symptoms occur
c. Time of day when symptoms occur
d. Severity of symptoms

9. Intermountain Health Care (IHC) identified four potential solutions to the problem of the rising cost of treating rhinitis. Please select the option that was not identified as a potential solution:

a. Enhancing the diagnostic process with the use of a simple tool

b. Education for the patient, physician, and employer

c. Implementation of an intervention program

d. Empiric therapy for rhinitis symptoms

10. In order to develop a comprehensive intervention program, IHC is planning to use a number of resources. Please select the one option below that was mentioned as part of the strategy:

a. Letters to the editor

b. Physician and patient letters

c. More allergy clinics

\section{Request for Pharmacy Continuing Education Credit}

I have read the supplement tilled "New Challenges to Old Standards in the Treatment of Rhinitis," printed with the Journal of Managed Care Pharmacyß and am requesting pharmacy continuing education (CE) credit.

PLEASE PRINT THE FOLLOWING INFORMATION:

Daytime Telephone Number

Please return this completed Post-test plus the Evaluation and Participation forms to the University of Texas as follows: Jill Williams, University of Texas, College of Pharmacy, Pharmacy Continuing Education, Room 5.102, Austin, TX 78712-1074. For credil, these forms must reach the University of Texas College of Pharmacy by January 31, 2003. CE certificates will be mailed to your address above as soon as possible after receipt of the CE test and evaluation and participation forms. The program is sponsored by an unrestricted educational grant from Wallace Laboratories. 